This manuscript is a preprint and is in preparation for submission to Environmental Research Letters. The manuscript has not yet undergone peer review. If accepted, the published version of this manuscript will be posted here. Please feel free to contact the authors with any questions or feedback. 


\title{
Plants as sensors: vegetation response to rainfall predicts subsurface water storage capacity in Mediterranean climates
}

\author{
David N. Dralle \\ E-mail: david.dralledcsus.edu \\ Department of Geology, Sacramento State University, Sacramento, CA, USA
}

W. Jesse Hahm

Department of Geography, Simon Fraser University, Burnaby, BC, Canada

\section{Daniella M. Rempe}

Jackson School of Geosciences, University of Texas at Austin, Austin, TX, USA

\section{Nathaniel J. Karst}

Department of Mathematics, Babson College, Wellesley, MA, USA

\section{Leander D. L. Anderegg}

Department of Integrative Biology, University of California at Berkeley, Berkeley, CA, USA

\section{Sally E. Thompson}

Civil, Environmental, and Mining Engineering, The University of Western Australia, Perth, Australia

\section{Todd E. Dawson}

Department of Integrative Biology, University of California at Berkeley, Berkeley, CA, USA

\section{William E. Dietrich}

Earth and Planetary Sciences, University of California at Berkeley, Berkeley, CA, USA

\begin{abstract}
Methods are lacking to characterize critical zone (CZ) structure at spatial scales relevant to earth system and dynamic global vegetation models. This knowledge gap results in poor quantification of $\mathrm{CZ}$ plant-available water storage capacity, hindering realistic prediction of the response of plants and streamflow to anticipated changes in the hydrological cycle. Here, we exploit the phase offset between water and energy delivery in rain-dominated Mediterranean climates to use plants as sensors to infer belowground water storage capacity. We hypothesize that if the magnitude of stored plant-available subsurface water is the primary control on dry season plant water use, then (remotely sensed) measures of transpiration may be used to infer rooting zone storage capacity. We encapsulate this idea within an ecohydrological
\end{abstract}


modeling framework that describes how the stochastic properties of rainfall interact with storage capacity on intra-annual timescales to control annual variations in plant-available water storage, and thus dry season plant water use. The model reveals that where storage capacity is high relative to mean annual rainfall, plant-available water storage is not replenished in all years, and so storage and thus plant water use are sensitive to annual total rainfall. Where storage capacity is low, storage is typically replenished but can be depleted rapidly between storm events, resulting in plant insensitivity to annual total rainfall but sensitivity to spring rainfall patterns. Both high and low storage capacity result in relatively highly variable stored water for summer, and thus predicted highly variable summer transpiration; in contrast, variability is minimized at intermediate storage capacity. The model captures these diverse responses of stored water (and consequently summer vegetation water use) - as mediated by water storage capacity - to precipitation dynamics. Consequently, we show that a simple model inversion can be used to estimate rooting zone water storage capacity. We validate model inversion predictions using direct observations of plant-available water storage capacity in soils and weathered bedrock at two intensively monitored sites in the Northern California Coast Ranges. The model accurately predicts the magnitude of the combined dry season soil and rock moisture loss that supports transpiration, in contrast to existing soils maps, which underestimate plant-available water storage by up to a factor of three. Strongly contrasting weathering profiles and hence porosity structures at the study sites demonstrate the method is robust across diverse modes of storage and runoff generation. 


\section{Introduction}

Measuring and predicting spatial variations in subsurface critical zone $(\mathrm{CZ})$ architecture is an exciting but challenging earth science research frontier (Riebe et al., 2017; Pelletier et al., 2016; Grant and Dietrich, 2017). One key CZ property central to understanding the ecohydrological function of landscapes is the capacity for the subsurface to store and release water. While maps of near-surface soil and its water storage properties exist (Geza and McCray, 2008; Entekhabi et al., 2010), information on whole-CZ subsurface properties, including the saprolite and weathered bedrock below near-surface soils, is generally lacking at large spatial scales. Fan et al. (2019) highlight the need to better constrain the subsurface $\mathrm{CZ}$ and its representation in models, noting that $\mathrm{CZ}$ architecture impacts, among other things, belowground water storage properties (including the dynamic water storage capacity, i.e., the difference between maximum and minimum possible water content). These properties mediate runoff response to rainfall, impact the Earth's near-surface energy budget, determine baseflow during periods of no rain, and regulate groundwater storage and water quality as well as vegetation water use and productivity. Recently, Klos et al. (2018) reviewed water storage attributes of the critical zone, and identified 'plant accessible water storage capacity' (here denoted $S_{\max }[\mathrm{L}]$ ) as the volume of subsurface void space available to store water for use by vegetation. Although this concept is frequently used in both modeling and empirical frameworks (Porporato et al., 2004; Seyfried et al., 2009), intensive field campaigns are typically required to estimate this key ecological variable (Rempe and Dietrich, 2018).

Understanding how much water can be stored belowground for vegetation is extremely important in rain-dominated seasonally dry or drought-prone regions. In these regions, subsurface storage alone supports plant water use during dry periods if fog or dew input is negligible. Mediterranean ecosystems have also been singled out as biodiversity hotspots threatened by climate change (Lehner et al., 2017; Swain et al., 2018; Cowling et al., 1996). There is also evidence that dynamic global vegetation models have the least predictive power in Mediterranean regions, possibly due to misrepresentation of subsurface water storage capacity (Morales et al., 2005). Because rainfall is minimal during times of peak energy availability, summer water use and productivity in rain-dominated Mediterranean regions are constrained by the availability of water storage carried over from the wet season in soil, rock moisture, snowpack, and groundwater (Hahm et al., 2019b; Graham et al., 2010; Rempe and Dietrich, 2018). The importance of this seasonal carryover of water storage, particularly within deeper layers below the soil, for ecosystem productivity and water use has been identified by numerous investigators (Klos et al., 2018; Garcia and Tague, 2015; Rempe and Dietrich, 2018; Hahm et al., 2019b; Lewis and Burgy, 1964; Zwieniecki and Newton, 1996; Arkley, 1981; Anderson et al., 1995; Rose et al., 2003; Rempe and Dietrich, 2018; Eliades et al., 2018). For example, Hahm et al. (2019b) recently revealed through intensive hillslopescale monitoring in the Northern California Coast Ranges how the magnitude of plantavailable water storage is capped by subsurface water storage capacity, which is in turn related to the depth and extent of weathering in the CZ. Hahm et al. (2019a) also demonstrated, via remote-sensing of plant greenness and water-balance tracking, that subsurface water storage 
capacity can decouple summer water availability, and thus plant productivity, from year-toyear rainfall variability. However, methods and datasets that explicitly map $\mathrm{CZ}$ structure are generally lacking at larger spatial scales, or have limited applicability. For example, water balance approaches typically rely on sparsely distributed stream gauging stations (e.g. Hahm et al., 2019a). Microwave-based satellite observations of soil moisture storage dynamics are extensive but limited to the very shallow near surface (Entekhabi et al., 2010). Soils databases are often interpolated between sparsely spaced soil pits in montane areas (Natural Resources Conservation Service, 2019), and similarly do not extend at depth to capture the entire relevant range of plant-accessible water. Space-based gravity observations (Swenson et al., 2003) and ground-based surface deformation (Argus et al., 2014) are sensitive to changes in water storage, but over extremely large spatial scales. They may also potentially incorporate changes in storage within deep aquifers out of reach of most plant communities.

One promising path forward is to leverage plants as sensors of water availability, and therefore as windows into subsurface water storage dynamics (Thompson et al., 2011; Thompson and Katul, 2011). Plant productivity and water use are sensitive to both water and energy availability (Holdridge, 1947; Stephenson, 1990). Thus, if the interactions between rainfall and subsurface water storage capacity (which can be modeled) determine how much water is stored and available to vegetation, then subsurface $\mathrm{CZ}$ water storage properties may be inferred by combining remotely sensed measures of vegetation activity with model inversion frameworks.

Here, we develop a simple stochastic model for rooting zone water storage, expanding on recent modeling advances to investigate how plant-available water storage capacity $\left(S_{\max }\right)$ mediates dry season evapotranspiration (ET) in rain-dominated Mediterranean climates. The model introduces a simplified representation of ecohydrological seasonality within existing stochastic modeling frameworks (e.g. Zanardo et al., 2012; Dralle and Thompson, 2016; Feng et al., 2015) to explicitly examine the interaction between intra-seasonal features of rainfall and storage capacity. We then demonstrate that the model can be used as an inversion tool to predict $S_{\text {max }}$, under the basic premise that year-to-year variability in summer plant water use should reflect year-to-year variability in subsurface water availability, which manifests through the interaction of $S_{\max }$ and rainfall.

Using a remotely sensed ET dataset and empirical rainfall statistics, we find that the inversion accurately predicts $S_{\max }$ at two Eel River Critical Zone Observatory (ERCZO) field sites in the Northern California Coast Ranges where independent hillslope- and catchmentscale observations of $S_{\max }$ have previously been directly measured.

\section{Methods}

We simulate wet season rooting zone water storage $(S[\mathrm{~L}])$ with a 1-d model that provides a minimal description of ecohydrological dynamics in the rooting zone. The rooting zone water balance (illustrated in Figure 1) can be expressed as:

$$
\frac{d S}{d t}=P(t)-E T[S(t)]-Q[S(t), P(t)]
$$


where $\mathrm{P}[\mathrm{L} / \mathrm{T}]$ is rainfall entering the rooting zone, ET $[\mathrm{L} / \mathrm{T}]$ represents evapotranspiration losses from the rooting zone, and $\mathrm{Q}[\mathrm{L} / \mathrm{T}]$ represents drainage from the rooting zone. $S$ is defined as the volume of water (expressed as a depth of liquid water) stored in the rooting zone that is accessible to vegetation, which ranges from 0 , representing a wilting point, to $S_{\text {max }}$, representing field capacity. Evapotranspiration increases linearly from zero at $S=0$ to a maximum allowable evapotranspiration $\left(E T_{\max }\right.$, set to PET) at $S=S_{\max }$, where $P E T$ is the potential evapotranspiration. PET is explicitly modeled and assumed constant during the wet season, and is parameterized as the average PET over the entire wet season. At the daily timescale, rainfall volumes entering the rooting zone that would increase storage above $S_{\max }$ are balanced by instantaneous drainage $(D)$, so that $S$ is always less than or equal to $S_{\max }$. We note that the water storage capacity $\left(S_{\max }\right)$ can be written in terms of typical parameters in simple soil moisture models (e.g. Porporato et al., 2004): a porosity $n$, a rooting zone depth $Z_{r}$, a field capacity $s_{f c}$, and a wilting point $s_{w p}$, such that $S_{\max }=n Z_{r}\left(s_{f c}-s_{w p}\right)$; here, $s_{f c}$ and $s_{w p}$ describe relative pore-space water contents, not water potentials, i.e., $s=\theta / n$, where $\theta$ is the volumetric water content.

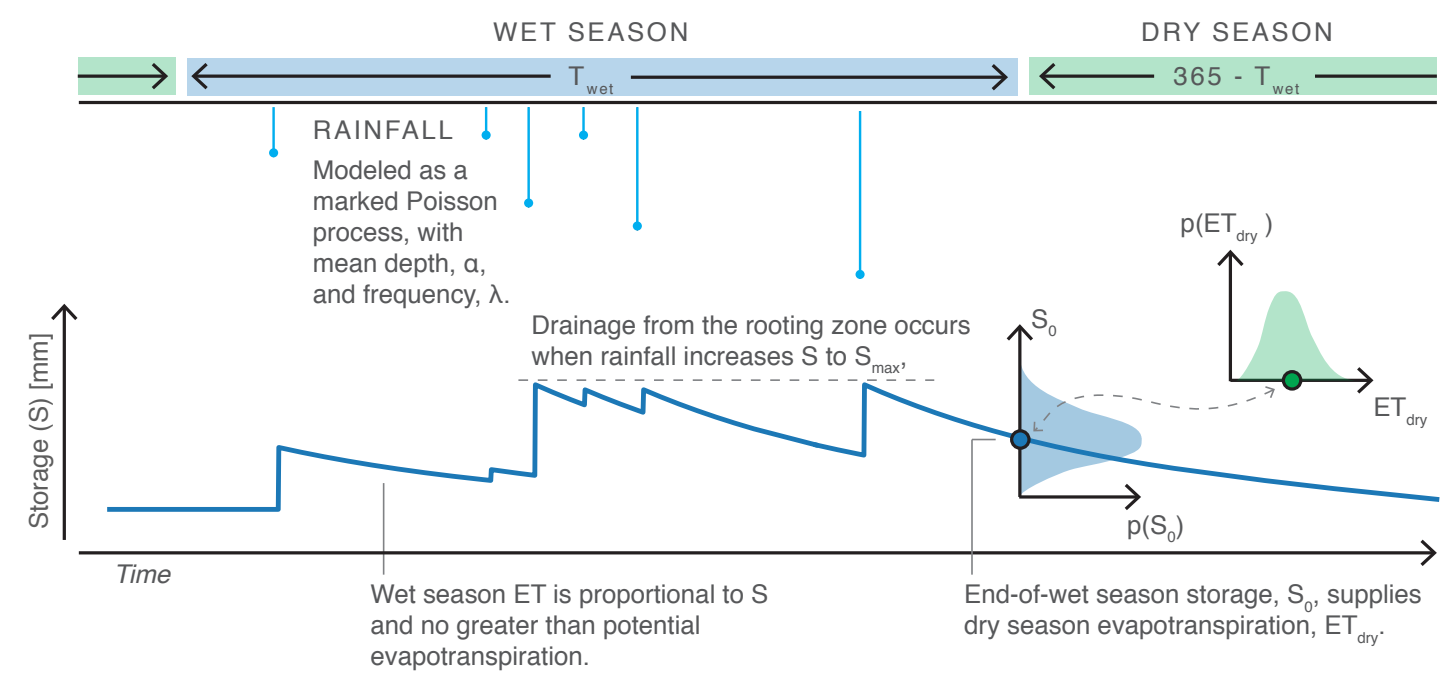

Figure 1. Stochastic rooting zone storage model. A single illustrative wet season rooting zone water storage trace is shown (dark blue line). Storage rises rapidly in response to rain events (light blue vertical lines on upper axis) and declines slowly due to evapotranspiration in between rain events. The end-of-wet season water storage, $S_{0}$ (filled blue circle), is one of many possibilities, whose mean and standard deviation are represented by the probability density function, denoted by $p\left(S_{0}\right)$. $S_{0}$ determines (and is directly proportional to) the amount of dry season evapotranspiration (filled green circle).

Importantly, the model does not restrict rooting zone water storage to soils alone; $S$ may include storage within underlying weathered bedrock. The model is strictly applicable to plant water use from an unsaturated (vadose) zone, however, for values of $s_{f c}$ close to 1 (saturation), it may be an appropriate representation of water storage dynamics and plant use from saturated portions of the subsurface. 
2.0.1. Incorporating rainfall statistics as a stochastic process To understand how $S_{\max }$ mediates plant-available water storage from year to year for realistic rainfall patterns, we use a stochastic Poisson process to represent precipitation (Milly, 1993; Porporato et al., 2004; Good et al., 2017), assuming rainfall events occur at random with frequency $\lambda\left[\mathrm{T}^{-1}\right]$. Due to the properties of Poisson processes, the inter-arrival times between rainfall events can be described with an exponential probability density function with mean $1 / \lambda$. Upon the occurrence of a rainfall event, the event depth (amount of fallen rain) is also described using an exponential distribution with mean $\alpha$ [L].

2.0.2. Seasonality (Porporato et al., 2004) found a steady-state solution for Equation 1 under stationary climate conditions (when the statistics of precipitation, $\alpha$ and $\lambda$, do not change in time), and showed that the rooting zone water storage follows a truncated gamma probability distribution (such that $S$ is greater than zero and less than or equal to $S_{\max }$ ). However, such a model does not resolve intra-seasonal patterns of wetting in climates where rainfall is strongly seasonal. A transient model is thus required to use observations of plant water use to estimate $S_{\text {max }}$, although to our knowledge, the unsteady, stochastic formulation of Equation 1 cannot be solved in closed form. Other authors have found approximate solutions (Feng et al., 2015), but we have found that the accuracy of these approximations decreases when the magnitude of average total annual rainfall is comparable to subsurface storage capacity. We therefore solve the governing equation using Monte Carlo simulations (for implementation details, see code availability statement).

2.0.3. Initial conditions The rooting zone water storage, $S$, initial condition at the start of the wet season is assumed to be zero, and rainfall seasonality is assumed to be binary, with no rainfall during the dry season, and stationary hydroclimatic features (constant $\alpha, \lambda$, and $E T_{\max }$ ) during the wet season. The first assumption is reasonable if dry season rainfall is negligible, and if water use proceeds according to the same rules as the wet season; that is, water use due to actual evapotranspiration increases linearly from 0 when $S=0$ to $E T_{\max }$ when $S=S_{\text {max }}$. Without additional rainfall inputs, this implies an exponential decline in storage (and, because water use is proportional to storage, also an exponential decline in rates of actual evapotranspiration) over the dry season, and therefore small end of summer storage relative to $S_{0}$.

\subsection{Role of $E T_{d r y}$ for predicting $S_{\max }$}

We wish to infer rooting zone water storage capacity as a function of hydroclimate and vegetation water use. The model maps the interaction between winter hydroclimate and subsurface water storage capacity to the start of dry season storage, $S_{0}$, which is not easily measured or observed. We therefore exploit the fact that in seasonally dry climates, the more readily observable magnitude of dry season evapotranspiration typically will scale linearly with $S_{0}$ (Feng et al., 2017). That is, dry season water use will increase proportionally with $S_{0}$. While we do not explicitly model dry season evapotranspiration, under the model 
assumptions, dry season evapotranspiration, $E T_{d r y}$, will equal $S_{0}-S_{0} \exp \left(-S / S_{\max } \cdot E T_{\max }\right.$. $\left.T_{d}\right)=S_{0}\left(1-\exp \left(-S / S_{\max } \cdot E T_{\max } \cdot T_{d}\right)\right)$, where $T_{d}$ is the duration of the dry season (365 $-T_{w}$ ). The final equality shows that the volume of water evapotranspired during the dry season is proportional to dry season initial storage $\left(S_{0}\right)$, which in turn is set by the stochastic realization of that year's wet season rainfall. This relationship between observable plant water use and subsurface storage dynamics is a key linkage that we leverage to infer subsurface CZ storage properties.

\subsection{Model inversion for estimating $S_{\max }$}

If $E T_{d r y} \propto S_{0}$, then $C V\left[E T_{d r y}\right]=C V\left[S_{0}\right]$, where $C V$ is the coefficient of variation, equal to the standard deviation divided by the mean. That is, because of proportionality between the two variables, relative variability in one can be used interchangeably to estimate relative variability in the other. This provides a method for using remotely sensed measures of dry season vegetation water use $\left(E T_{d r y}\right)$ as an indicator of subsurface storage dynamics. Specifically, an estimate of $C V\left[E T_{d r y}\right]$ from satellite remote-sensing data can be substituted for $C V\left[S_{0}\right]$, which is more difficult to observe directly. In the Results, we demonstrate that knowledge of $C V\left[S_{0}\right]=C V\left[E T_{d r y}\right]$ can be used to directly estimate $S_{\max }$. This method for estimating storage is more widely applicable than the flux-tracking methodology presented in Hahm et al. (2019a), because it does not rely on closure of the water budget which, crucially, requires unimpaired stream gauging. Moreover, the storage capacities that could be inferred from flux tracking are total catchment dynamic water storages, rather than root-zone plantavailable water storage capacities, which is estimated here.

\subsection{Case studies: Model application and inversion at well-characterized field sites}

To parameterize the stochastic storage model, we rely on hydroclimatic records from two study watersheds within the Eel River Critical Zone Observatory: Elder Creek $\left(16.9 \mathrm{~km}^{2}\right)$ and Dry Creek $\left(3.5 \mathrm{~km}^{2}\right)$. Intensive hillslope monitoring has been ongoing at Elder Creek for roughly a decade (Salve et al., 2012; Link et al., 2014; Oshun et al., 2016; Kim et al., 2014; Hahm et al., 2019b; Lovill et al., 2018; Rempe and Dietrich, 2018), and at Dry Creek since 2015 (Hahm et al., 2019b; Dralle et al., 2018; Lovill et al., 2018). The regional Mediterranean climate here has warm, dry summers followed by cool, wet winters (Peel et al., 2007). Elder Creek receives approximately $2000 \mathrm{~mm}$ of annual precipitation, and Dry Creek approximately $1800 \mathrm{~mm}$ (PRISM Climate Group, 2004), almost all of which falls as rain, primarily between November and April. Although it rains more at Elder Creek, the greater canopy cover there (see below) results in greater interception and an amount of rainfall that actually reaches the ground surface that is similar to Dry Creek. These sites lie within the Franciscan Formation, an exhumed subduction complex that is locally comprised of three coast-parallel (roughly north-south) belts (Blake Jr and Jones, 1974). The Elder Creek watershed is located in the westernmost Coastal Belt, which is comprised mostly of shale (argillite), with lesser components of sandstone and conglomerate (Jayko et al., 1989; Salve et al., 2012; Lovill et al., 2018). Dry Creek watershed is about $20 \mathrm{~km}$ to the southeast and is underlain by the Central 
Belt, which consists of mélange with an intensely sheared, primarily argillaceous matrix with coherent blocks of various lithologies, dominated by sandstone (Blake Jr and Jones, 1974; Lovill et al., 2018).

Despite the proximity and similar climates of the sites, their contrasting lithologies lead to dramatic differences in the depth of weathering and structure of the critical zone, and corresponding large differences in storage dynamics (Hahm et al., 2019b). Hahm et al. (2019b) demonstrate that lithologically controlled differences in water storage capacity explain the contrasting vegetation communities between the two sites: the limited extent of weathering at Dry Creek results in low plant-available water storage capacity, and correspondingly an oak savanna plant community typically associated with much lower rainfall, while the thick subsurface $\mathrm{CZ}$ at Elder Creek seasonally stores enough water to support dense evergreen forest. Dralle et al. (2018) develop a mass-balance based approach to estimate volumes of seasonally dynamic water storage in the subsurface that do not generate pressure gradients that drive streamflow generation, and suggest that these water volumes may be used to estimate plant available water storage capacity. Rempe and Dietrich (2018) measure unsaturated, ecologically-accessed water storage in weathered, fractured rock and saprolite at the Elder Creek site, demonstrating that this rock moisture supplies the vast majority ( $>$ $300 \mathrm{~mm}$ ) of transpiration water during the protracted dry season. Collectively, these papers provide multiple independent estimates of $S_{\max }$ (100-200 mm at Dry Creek, and 300-400 mm at Elder Creek; mostly within weathered bedrock below soils) that can be used to evaluate the results of the stochastic modeling framework.

\subsubsection{Data requirements The model requires wet season rainfall statistics ( $\lambda$ and $\alpha$ ), average} wet season $E_{\max }$, and wet season length $T_{w}[\mathrm{~T}]$, all of which are assumed constant and empirically calculated and reported in Table 1. Rainfall is measured with tipping bucket rain gauges, and corrected for wind-induced undercatch and interception (see Dralle et al. (2018) for details). Although the Poisson rainfall model assumes that rainfall event occurrences are independent in time, rainfall events are often temporally autocorrelated along the California coast. Therefore, we define a rainfall event as any consecutive period of days with non-zero rainfall, with a total event depth equal to the sum of rainfall over the consecutive period, and an occurrence date marked halfway through the event. $E T_{\max }$ is set equal to potential evapotranspiration, which we compute using ERCZO weather station data and the Hargreaves method (Dralle et al., 2018). To determine the length $\left(T_{w}\right)$ and boundaries of the wet season we first add the rain on each day of the year across all years to collapse the rainfall record into a single composite representative year. Beginning in the heart of the dry season (August 1), we define the start of the wet season $\left(D_{2.5}\right)$ as the day on which 2.5 percent of the cumulative rain has fallen in the composite representative year, and the end of the wet season $\left(D_{97.5}\right)$ as the day on which 97.5 percent of the cumulative rain has fallen. The number of days between these dates $\left(\left(D_{97.5}-D_{2.5}\right)\right.$ defines $T_{w}$. We acknowledge these cutoff values are subjective, and many possible definitions would likely be suitable. We found that other methods for estimating wet season length yielded similar results (e.g. (?Dralle and Thompson, 2016)), but found this method to be advantageous for three reasons: 1) We found that the slope of the 
cumulative rainfall distribution between the thresholds that emerged based on this definition is approximately linear (see acknowledgements for repository with supporting plots), which meets the model requirement of stationary rainfall statistics, 2) because wet season length is allowed to vary on a site-by-site basis depending on local climatology, and 3) The algorithm is simple and readily applicable across large spatial scales is good.

During the dry season months of June, July, and August negligible rain falls, and therefore variability in ET is likely attributable to storage conditions. We therefore use estimates of actual evapotranspiration during these months in the prediction of $S_{\max }$, and obtain these estimates from a biophysical evapotranspiration model that has been evaluated across California (Baldocchi et al., 2019). This ET dataset is available from 2001 to 2017. All 17 years of ET data used in this study are freely available, and provided with the code required to replicate results at https://github.com/daviddralle/storage_cvs/.

2.3.2. Simulation exercises We perform two simulation exercises; one to illustrate model output for a fixed climate and varying $S_{\max }$, and a second to infer $S_{\max }$ from $C V\left[E T_{d r y}\right]$ at the two case study sites.

Simulation exercise 1 In the first simulation exercise we use the model to illustrate seasonal patterns of wetting for three different values of total storage capacity, holding wet season length and climate statistics constant. Thirty years are simulated for each case to illustrate controls on $S_{0}$ and its inter-annual variability. This reveals how the end-of-wet season storage magnitude and relative variability depend on the interaction between water storage capacity and rainfall statistics.

Simulation exercise 2 The second simulation computes $C V\left[S_{0}\right]$ across a range of values of $S_{\max }$ for the hydroclimatic parameters in Table 1 . We use the relationship between $C V\left[S_{0}\right]$ and $S_{\max }$ outlined in Section 2.2, along with estimates of dry season evapotranspiration variability, to predict $S_{\max }$ at the two study sites. We then compare these predictions to independently determined field-based estimates of $S_{\max }$.

\section{Results}

Table 1 summarizes model parameters from ERCZO climate data.

\subsection{Simulation exercise 1}

Figure 2 depicts Monte Carlo simulation of water storage in the rooting zone for different water storage capacities using the parameters in Table 1. Note that, in all three panels, an equivalent absolute moisture loss from the rooting zone results in different relative declines in the storage, because the total volume of storage varies in each case.

In Fig. 2a, because the storage capacity is small relative to the mean annual rainfall, $\mathrm{S}$ reaches $S_{\max }$ early and often (grey line traces of individual yearly simulations reach the top 


\begin{tabular}{|l|l|}
\hline Parameter & Value \\
\hline$T_{w}$ [days] & $224($ Oct 4 to May 15$)$ \\
\hline$E T_{\max }$, wet season $[\mathrm{mm} /$ day] & 1.85 \\
\hline$\lambda$, wet season $[1 /$ day] & 0.115 \\
\hline$\alpha$, wet season $[\mathrm{mm}]$ & 65.8 \\
\hline
\end{tabular}

Table 1. Empirical model parameters calculated for the study sites. The same parameters are used at both Dry Creek and Elder Creek (see Site Descriptions). Although not an explicit parameter in the model, average total wet season rainfall is equal to the product of $T_{w}, \lambda$, and $\alpha$.

of the plot). Nevertheless, wet season evapotranspiration between rain events draws down this limited storage rapidly, resulting in highly variable year-to-year storage conditions at the end of the wet season. Consequently, $S_{0}$ varies strongly relative to its mean, and is sensitive to the timing and magnitude of late wet season rainfall.

In contrast, in Fig. 2c, the storage capacity is large relative to the mean annual rainfall, and $S_{\max }$ is not reached in many simulated years. This also results in highly variable $S_{0}$. However, because evapotranspiration depletes the large storage reservoir more slowly than in Fig. 2a (smaller inter-event declines in $\mathrm{S}$ ), $S_{0}$ variability is controlled by total wet season rainfall rather than the timing and magnitude of late wet season rain events.

Fig. 2b reveals an intermediate case, in which the storage capacity is small enough relative to rainfall that $S_{\max }$ is reached in almost all years, but large enough that storage is not significantly reduced (in a relative sense) during rainless periods. This leads to a low value for $\mathrm{CV}\left[S_{0}\right]$, and the annual value of $S_{0}$ being relatively insensitive to both the total amount of wet season rainfall and the timing and magnitude of the last rain events.

\subsection{Simulation exercise 2}

In the second exercise, we run Monte Carlo simulations of the model with ERCZO hydroclimatic parameters (Table 1) to obtain theoretical estimates of $C V\left[S_{0}\right]$ (that is, the $\mathrm{CV}$ of the end of wet season storage in the simulations in Fig. 2) for values of $S_{\max }$ ranging from 0 to $1000 \mathrm{~mm}$. Model output is plotted in Figure 3 with a solid black line. Note that the $\mathrm{CV}$ values differ slightly between Figures 2 and 3. This is because the number of simulated years in Figure 2 is limited to 30 for illustrative purposes, and so the estimated value of CV has not converged to the theoretical, limiting value presented in Figure 3.

Although we are unable to directly measure $C V\left[S_{0}\right]$ at each site, the mathematical equivalence between $C V\left[S_{0}\right]$ and $C V\left[E T_{d r y}\right]$ (see Section 2.2) means that satellite-observed values of $C V\left[E T_{d r y}\right]$ can be used to locate each site on the vertical axis in Figure 3, in order to estimate $S_{\text {max }}$. This specific procedure, outlined in general below, and implemented for our two sites in the accompanying Jupyter (Python) notebooks hosted on Github, is equivalent to finding the mathematical inverse of the black curve in Figure 3:

(i) Calculate $C V\left[E T_{d r y}\right]$ from satellite-based observations of evapotranspiration.

(ii) Use the equivalency $C V\left[E T_{d r y}\right]=C V\left[S_{0}\right]$ to locate each site on the vertical axis. 

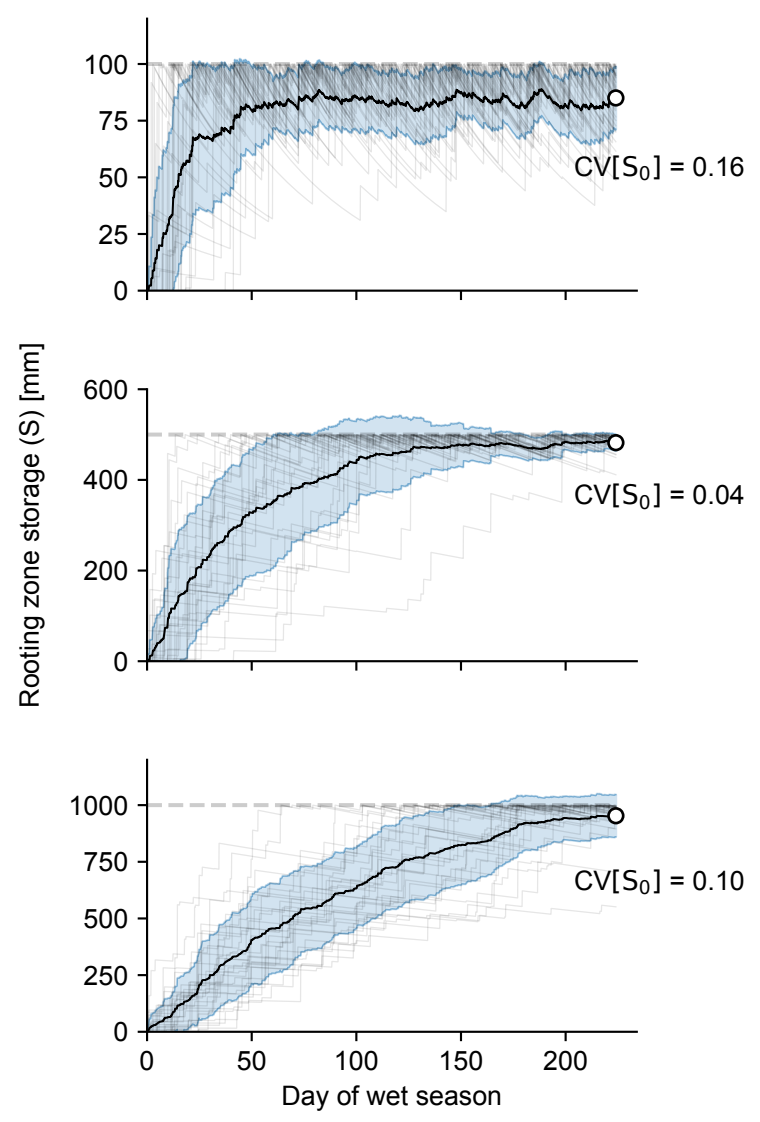

Figure 2. Rooting zone water storage dynamics for increasing $S_{\max }(100 \mathrm{~mm}$ (a), $500 \mathrm{~mm}$ (b), and $1000 \mathrm{~mm}(\mathrm{c}))$. Thirty Monte Carlo realizations of model storage output are plotted in light gray traces for each case. The seasonal progression of the ensemble mean is denoted with a bold black line, with a start-of-dry season value (the mean of $S_{0}$ ) shown with a black point. Blue envelopes represent plus or minus one standard deviation about the mean.

(iii) Starting on the vertical axis, trace each site's value of $C V\left[S_{0}\right]$ (blue and red dashed lines) horizontally to their intersection with the theoretical curve.

(iv) From the theoretical curve, drop down to the horizontal axis to obtain an estimate of $S_{\max }$.

Inferred volumes of plant-available water storage compare well with direct, independent estimates of plant-available water storage made at the two sites. Using downhole neutron probes and soil time domain reflectometry, Rempe and Dietrich (2018) estimate that the seasonal change in vadose zone water content (which we interpret as plant-available water storage) at Elder Creek is between 300 and $400 \mathrm{~mm}$. Dralle et al. (2018) used wells to estimate plant-available water storage at Dry Creek between 120 and $200 \mathrm{~mm}$.

Values of $S_{\max }$ computed through the inversion procedure are not typically unique because the theoretical curve $\mathrm{CV}\left[S_{0}\right]$ vs. $S_{\max }$ is not monotonic (see Figure 3 ). This nonuniqueness must be resolved when mapping model predictions of $C V\left[S_{0}\right]$ and observations of $C V\left[E T_{d r y}\right]$ from the remotely sensed ET dataset to $\mathrm{S}_{\max }$. 


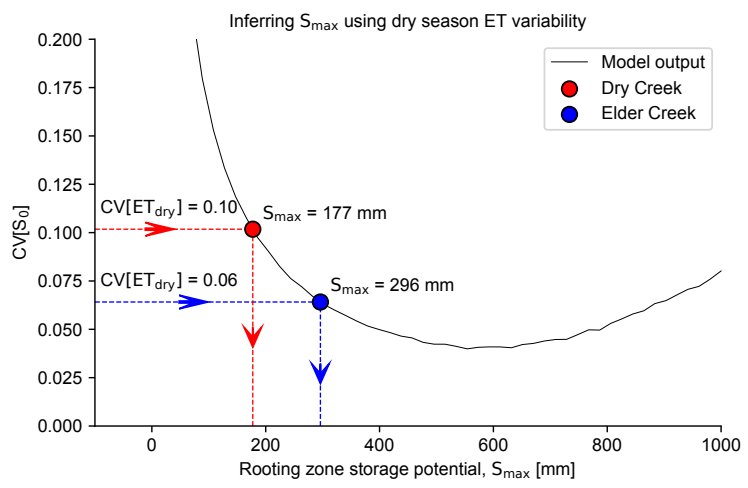

Figure 3. $S_{\max }$ is inferred from dry season ET variability, based on the relationship between $S_{\max }$ and the coefficient of variation of end-of-wet season storage, $C V\left[S_{0}\right]$. The inference is made possible by equating the more readily measurable $C V[E T]$ with $C V\left[S_{0}\right]$. Measured values of $C V[E T]\left(=C V\left[S_{0}\right]\right)$ are plotted for Elder (blue) and Dry Creek (red) on the y-axis, and accurately predict the independently measured $S_{\max }$ for these sites (shown via horizontal bars under the $\mathrm{x}$-axis).

Fig. 2 reveals graphically why this non-monotonic behavior arises from the hydroclimatic dynamics of the simple 1-d storage reservoir: $\mathrm{CV}\left[S_{0}\right]$ is minimized at an intermediate water storage capacity. The minimum is also clearly identified in Figure 3 near $S_{\max } \approx 600 \mathrm{~mm}$. To the left of this minimum, $\mathrm{CV}\left[S_{0}\right]$ increases because late wet season ET can rapidly deplete the small storage capacity, which may or may not be replenished by rainfall in the final weeks of the wet season. To the right of the minimum, $\mathrm{CV}\left[S_{0}\right]$ begins to increase because larger storage capacity increases sensitivity of $S_{0}$ to variations in total wet season precipitation. This suggests that if $\mathrm{ET}_{\mathrm{dry}}$ is sensitive (insensitive) to total wet season rainfall, the inversion procedure should map to the right (left) of the minimum on the modeled curve in Figure 3.

\section{TODO ADD SPRING RAINFALL PLOT TO FIGURE 4.}

Figure 4 applies this simple heuristic to resolve the inversion non-uniqueness, plotting $\mathrm{ET}_{\mathrm{dry}}$ at both sites against total wet season precipitation. Spearman rank correlation values ( $\rho$ in plot titles) and levels of significance ( $p$ in plot titles, with $p>0.05$ indicating statistically insignificant rank correlation coefficients) signify that $\mathrm{ET}_{\mathrm{dry}}$ is not sensitive to total wet season precipitation in either watershed. This suggests that the inversion procedure should map to the left side of the theoretical curve at both Elder Creek and Dry Creek, consistent with the independently estimated $\mathrm{S}_{\max }$ values.

\section{Discussion}

A reduced complexity stochastic model for rooting zone water storage dynamics in Mediterranean climates demonstrates that plant response to climatic variability can be used to estimate rooting zone water storage capacity in the critical zone. At two rain-dominated sites in Northern California with strongly contrasting weathering profiles, model predictions 


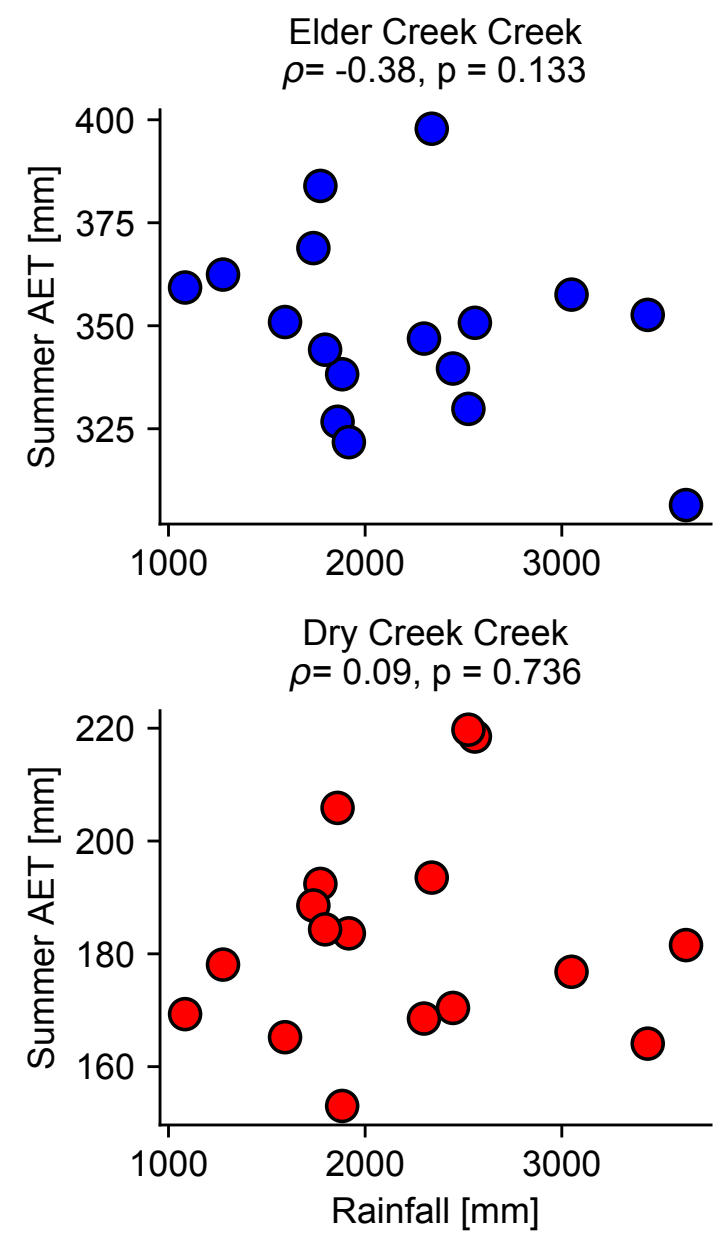

Figure 4. Comparing the response of dry season ET to total wet season cumulative rainfall resolves the non-uniqueness of the inferred $S_{\max }$ in Figure 3. Dry season ET is insensitive to total wet season rain at both sites, indicating that storage capacity is low relative to average rainfall at both sites (behavior more similar to case a than case c in Fig. 2), such that both cases fall in the domain to the left of the minimum in Fig. 3.

closely match direct measurements of storage capacity in shallow soils and underlying weathered bedrock.

\subsection{Limitations of the modeling approach}

A novel contribution of this paper is the development and validation of a relatively simple and widely applicable method in Mediterranean climates to determine subsurface plant-available water storage capacity, a key ecohydrological parameter. However, the method is only strictly valid in rain-dominated Mediterranean regions, limiting its application. Future work will focus on development of more general methods that can be applied to more diverse climates.

A second limitation of the method is the reliance on remotely sensed measures of vegetation water use. We used the BESS evapotranspiration dataset presented for California in Baldocchi et al. (2019), which importantly does not include any specific representation of the 
subsurface. Other evapotranspiration models which explicitly incorporate soil water balance modeling for ET estimation should not be used for the method presented here (Martens et al., 2017), precisely because they make assumptions about the subsurface water storage capacity that our approach is designed to estimate. By relying primarily on remotely sensed spectral signatures, ET datasets like the one we used could be biased in situations where plant functional group phenology undergoes minimal change across a range of transpiration rates. This should be explored further, but we note that at the sites we studied, as is the case in much of California, there is relatively large seasonal phenological variation (Hahm et al., 2019a). One other potentially confounding factor in our analysis is the extent to which year-to-year variation in summer energy supply might impact dry season plant water use. Because plants across California are typically water-limited rather than energy-limited in the summer dry season (i.e., PET greatly exceeds ET), this is unlikely to matter much, as Hahm et al. (2019a) found.

Finally, the model representation of subsurface water runoff and storage dynamics is highly simplified. All rainfall is assumed to infiltrate, such that no Hortonian overland flow occurs, limiting the scope of the model's applicability. We are also uncertain as to whether deeper rooting profiles, such as those observed in the Elder Creek watershed, can be usefully modeled within a framework that treats the entire vadose zone as a homogeneous reservoir. Within riparian areas or low-lying areas, or in areas with shallow rooting depths or thin subsurface critical zones, water table dynamics in the near surface may play an important role in setting plant-available water storage capacity. Although this is not explicitly accounted for in the model, the Dry Creek catchment provides some evidence that where field capacity does not greatly differ from saturation (Dralle et al., 2018), the model still may be useful, and likely still provides better effective estimates of storage capacity than existing soils datasets.

\subsection{Ecosystem sensitivity to climate}

Understanding drivers of ecosystem sensitivity to climate is important for understanding the impacts of climate change on global biogeochemical cycles. Here, we focused on how the capacity for the subsurface to store water for vegetation use could control dry season water availability and hence productivity. We demonstrate that dependence of water use on storage capacity is more nuanced than is traditionally assumed. Too much or too little storage capacity - relative to annual rainfall - tends to increase the sensitivity of water use to rainfall variability, with sensitivity minimized at intermediate storage capacity. This result differs from other modeled findings, which suggest increasing $\mathrm{S}_{\max }$ monotonically increases plant water stress (Porporato et al., 2004; Zanardo et al., 2012). However, these studies did not consider the transient effects of seasonality. Seasonality has been examined in (Feng et al., 2015), but analytical simplifications relating to runoff mechanisms in that model lead to inaccuracies when storage capacity is small relative to annual rainfall.

Globally, rainfall patterns in many Mediterranean climate zones are predicted to change dramatically (Swain et al., 2018; Valdes-Abellan et al., 2017; Viola et al., 2016), though in distinct ways in different regions. In California for example, although mean annual rainfall 
is not predicted to change significantly, precipitation variability and event magnitudes are expected to increase (Swain et al., 2018). In contrast, mean annual rainfall totals are predicted to decrease significantly throughout the European Mediterranean climate region (Gao and Giorgi, 2008). The model presented here suggests that rooting zone storage capacity plays an important role in determining how vegetation might respond to these varied trends. For example, the thin grey line traces in Figure 2a show that at locations with low storage capacity relative to annual rainfall totals, spring rainfall patterns are the dominant control on annual variations in summer transpiration and thus presumably productivity. In such watersheds, shifts in intra-seasonal rainfall patterns, such as increased event magnitudes, may significantly alter start-of-summer rooting zone water storage. In contrast, the model predicts that large relative storage capacity in the rooting zone increases vegetation sensitivity to total rather than intra-seasonal dynamics of precipitation (Figure 2c). Locations with intermediately sized storage capacities (relative to typical values of annual rainfall) may be least sensitive to increases in rainfall volatility (Figure $2 b$ ).

\section{Conclusion}

Here we developed an ecohydrological model for Mediterranean climates that elucidates how water storage capacity and intra-annual rainfall patterns determine the sensitivity of plant water use to inter-annual rainfall variability. By assuming that dry season plant water use scales with the amount of end-of-winter wet season water storage, the model can be used to predict subsurface plant-available water storage capacity, an important yet presently challenging parameter to map at large spatial scales. We validated the predictions using independent, field-based estimates of subsurface plant-available water storage capacity at two sites in the Northern California Coast Ranges. By using plants as sensors to learn about subsurface water storage capacity, our work represents an advance in using remotely sensed ecohydrologic datasets to infer properties about the critical zone, including deeper weathered bedrock below shallow soils. Future efforts will be most fruitful if they can be validated with hillslope-scale subsurface observations, motivating greater observatory-style exploration of the critical zone across lithologic, climatic, and tectonic gradients.

\section{Data and code availability}

The data and code (written in Python) required to reproduce the analyses and figures in this study are available at https://github.com/daviddralle/storage_cvs/. 


\section{References}

MA Anderson, RC Graham, GJ Alyanakian, and DZ Martynn. Late summer water status of soils and weathered bedrock in a giant sequoia grove. Soil Science, 160(6):415-422, 1995.

Donald F Argus, Yuning Fu, and Felix W Landerer. Seasonal variation in total water storage in california inferred from gps observations of vertical land motion. Geophysical Research Letters, 41(6):1971-1980, 2014.

Rodney J Arkley. Soil moisture use by mixed conifer forest in a summer-dry climate 1. Soil Science Society of America Journal, 45(2):423-427, 1981.

Dennis Baldocchi, David Dralle, Chongya Jiang, and Youngryel Ryu. How much water is evaporated across california?: A multi-year assessment using a biophysical model forced with satellite remote sensing data. Water Resources Research, 2019.

M Clark Blake Jr and David L Jones. Origin of franciscan melanges in northern california. 1974.

Richard M Cowling, Philip W Rundel, Byron B Lamont, Mary Kalin Arroyo, and Margarita Arianoutsou. Plant diversity in mediterranean-climate regions. Trends in Ecology \& Evolution, 11(9):362-366, 1996.

David N Dralle and Sally E Thompson. A minimal probabilistic model for soil moisture in seasonally dry climates. Water Resources Research, 52(2):1507-1517, 2016.

David N Dralle, W Jesse Hahm, Daniella M Rempe, Nathaniel J Karst, Sally E Thompson, and William E Dietrich. Quantification of the seasonal hillslope water storage that does not drive streamflow. Hydrological processes, 32(13):1978-1992, 2018.

Marinos Eliades, Adriana Bruggeman, Maciek W Lubczynski, Andreas Christou, Corrado Camera, and Hakan Djuma. The water balance components of mediterranean pine trees on a steep mountain slope during two hydrologically contrasting years. Journal of hydrology, 562:712-724, 2018.

Dara Entekhabi, Eni G Njoku, Peggy E O’Neill, Kent H Kellogg, Wade T Crow, Wendy N Edelstein, Jared K Entin, Shawn D Goodman, Thomas J Jackson, Joel Johnson, et al. The soil moisture active passive (smap) mission. Proceedings of the IEEE, 98(5):704-716, 2010.

Ying Fan, Martyn Clark, David M Lawrence, Sean Swenson, LE Band, SL Brantley, PD Brooks, WE Dietrich, A Flores, G Grant, et al. Hillslope hydrology in global change research and earth system modeling. Water Resources Research, 2019.

Xue Feng, Amilcare Porporato, and Ignacio Rodriguez-Iturbe. Stochastic soil water balance under seasonal climates. Proceedings of the Royal Society A: Mathematical, Physical and Engineering Sciences, 471(2174):20140623, 2015.

Xue Feng, Todd E Dawson, David D Ackerly, Louis S Santiago, and Sally E Thompson. Reconciling seasonal hydraulic risk and plant water use through probabilistic soil-plant dynamics. Global change biology, 23(9):3758-3769, 2017. 
Xuejie Gao and Filippo Giorgi. Increased aridity in the mediterranean region under greenhouse gas forcing estimated from high resolution simulations with a regional climate model. Global and Planetary Change, 62(3-4):195-209, 2008.

E. S. Garcia and C. L. Tague. Subsurface storage capacity influences climate-evapotranspiration interactions in three western united states catchments. Hydrology and Earth System Sciences, 19(12):4845-4858, dec 2015. doi: 10.5194/ hess-19-4845-2015.

Mengistu Geza and John E McCray. Effects of soil data resolution on swat model stream flow and water quality predictions. Journal of environmental management, 88(3):393-406, 2008.

Stephen P Good, Georgianne W Moore, and Diego G Miralles. A mesic maximum in biological water use demarcates biome sensitivity to aridity shifts. Nature ecology \& evolution, 1(12):1883, 2017.

Robert Graham, Ann Rossi, and R. Hubbert. Rock to regolith conversion: Producing hospitable substrates for terrestrial ecosystems. GSA Today, pages 4-9, feb 2010. doi: 10.1130/gsat57a.1.

Gordon E Grant and William E Dietrich. The frontier beneath our feet. Water Resources Research, 53(4):2605-2609, 2017.

W J Hahm, D N Dralle, D M Rempe, A B Bryk, S E Thompson, T E Dawson, and W E Dietrich. Low subsurface water storage capacity relative to annual rainfall decouples mediterranean plant productivity and water use from rainfall variability. Geophysical Research Letters, 2019a.

W Jesse Hahm, Daniella M Rempe, David N Dralle, Todd E Dawson, Sky M Lovill, Alexander B Bryk, David L Bish, Juergen Schieber, and William E Dietrich. Lithologically controlled subsurface critical zone thickness and water storage capacity determine regional plant community composition. Water Resources Research, 2019b. doi: 10.1029/ 2018WR023760.

Leslie R Holdridge. Determination of world plant formations from simple climatic data. Science, 105(2727):367-368, 1947.

A S Jayko, M C Blake, R J McLaughlin, H N Ohlin, Ellen S D, and Kelsey H M. Reconnaissance geologic map of the covelo 30- by 60-minute quadrangle, northern california (no. mf-2001). 1989.

Hyojin Kim, James KB Bishop, William E Dietrich, and Inez Y Fung. Process dominance shift in solute chemistry as revealed by long-term high-frequency water chemistry observations of groundwater flowing through weathered argillite underlying a steep forested hillslope. Geochimica et Cosmochimica Acta, 140:1-19, 2014.

P. Zion Klos, Michael L. Goulden, Clifford S. Riebe, Christina L. Tague, A. Toby O'Geen, Brady A. Flinchum, Mohammad Safeeq, Martha H. Conklin, Stephen C. Hart, Asmeret Asefaw Berhe, Peter C. Hartsough, W. Steven Holbrook, and Roger C. Bales. 
Subsurface plant-accessible water in mountain ecosystems with a mediterranean climate. Wiley Interdisciplinary Reviews: Water, page e1277, feb 2018. doi: 10.1002/wat2.1277.

Flavio Lehner, Sloan Coats, Thomas F Stocker, Angeline G Pendergrass, Benjamin M Sanderson, Christoph C Raible, and Jason E Smerdon. Projected drought risk in $1.5 \mathrm{c}$ and 2 c warmer climates. Geophysical Research Letters, 44(14):7419-7428, 2017.

DC Lewis and Robert H Burgy. The relationship between oak tree roots and groundwater in fractured rock as determined by tritium tracing. Journal of Geophysical Research, 69(12): 2579-2588, 1964.

Percy Link, Kevin Simonin, Holly Maness, Jasper Oshun, Todd Dawson, and Inez Fung. Species differences in the seasonality of evergreen tree transpiration in a mediterranean climate: Analysis of multiyear, half-hourly sap flow observations. Water Resources Research, 50(3):1869-1894, 2014.

SM Lovill, WJ Hahm, and WE Dietrich. Drainage from the critical zone: Lithologic controls on the persistence and spatial extent of wetted channels during the summer dry season. Water Resources Research, 54(8):5702-5726, 2018.

Brecht Martens, Diego Gonzalez Miralles, Hans Lievens, Robin Van Der Schalie, Richard AM De Jeu, Diego Fernández-Prieto, Hylke E Beck, Wouter Dorigo, and Niko Verhoest. Gleam v3: Satellite-based land evaporation and root-zone soil moisture. Geoscientific Model Development, 10(5):1903-1925, 2017.

PCD Milly. An analytic solution of the stochastic storage problem applicable to soil water. Water Resources Research, 29(11):3755-3758, 1993.

Pablo Morales, Martin T Sykes, I Colin Prentice, Pete Smith, Benjamin Smith, Harald Bugmann, Bärbel Zierl, Pierre Friedlingstein, Nicolas Viovy, Santi Sabaté, et al. Comparing and evaluating process-based ecosystem model predictions of carbon and water fluxes in major european forest biomes. Global Change Biology, 11(12):2211-2233, 2005.

Natural Resources Conservation Service. Web soil survey. 2019.

Jasper Oshun, William E Dietrich, Todd E Dawson, and Inez Fung. Dynamic, structured heterogeneity of water isotopes inside hillslopes. Water Resources Research, 52(1):164$189,2016$.

Murray C Peel, Brian L Finlayson, and Thomas A McMahon. Updated world map of the köppen-geiger climate classification. Hydrology and earth system sciences discussions, 4 (2):439-473, 2007.

Jon D. Pelletier, Patrick D. Broxton, Pieter Hazenberg, Xubin Zeng, Peter A. Troch, GuoYue Niu, Zachary Williams, Michael A. Brunke, and David Gochis. A gridded global data set of soil, intact regolith, and sedimentary deposit thicknesses for regional and global land surface modeling. Journal of Advances in Modeling Earth Systems, 8(1): 41-65, jan 2016. doi: 10.1002/2015ms000526. URL https : / / doi . org/10 . $1002 \%$ 2F $2015 \mathrm{~ms} 000526$.

Porporato, Daly, and Rodriguez-Iturbe. Soil water balance and ecosystem response to climate change. The American Naturalist, 164(5):625, 2004. doi: 10.2307/3473173. 
PRISM Climate Group. Prism rainfall dataset. 2004. URL http://prism. oregonstate.edu.

Daniella M Rempe and William E Dietrich. Direct observations of rock moisture, a hidden component of the hydrologic cycle. Proceedings of the National Academy of Sciences, 115 (11):2664-2669, 2018.

Clifford S Riebe, W Jesse Hahm, and Susan L Brantley. Controls on deep critical zone architecture: a historical review and four testable hypotheses. Earth Surface Processes and Landforms, 42(1):128-156, 2017.

K Rose, R Graham, and D Parker. Water source utilization by pinus jeffreyi and arctostaphylos patula on thin soils over bedrock. Oecologia, 134(1):46-54, 2003.

Rohit Salve, Daniella M Rempe, and William E Dietrich. Rain, rock moisture dynamics, and the rapid response of perched groundwater in weathered, fractured argillite underlying a steep hillslope. Water Resources Research, 48(11), 2012.

M. S. Seyfried, L. E. Grant, D. Marks, A. Winstral, and J. McNamara. Simulated soil water storage effects on streamflow generation in a mountainous snowmelt environment, idaho, USA. Hydrological Processes, 23(6):858-873, mar 2009. doi: 10.1002/hyp.7211.

Nathan L Stephenson. Climatic control of vegetation distribution: the role of the water balance. The American Naturalist, 135(5):649-670, 1990.

Daniel L Swain, Baird Langenbrunner, J David Neelin, and Alex Hall. Increasing precipitation volatility in twenty-first-century california. Nature Climate Change, 8(5): 427, 2018.

Sean Swenson, John Wahr, and PCD Milly. Estimated accuracies of regional water storage variations inferred from the gravity recovery and climate experiment (grace). Water Resources Research, 39(8), 2003.

S. E. Thompson and G. G. Katul. Inferring ecosystem parameters from observation of vegetation patterns. Geophysical Research Letters, 38(20):n/a-n/a, oct 2011. doi: 10.1029/2011gl049182. URL https: / / doi . org/10.10292F2011g1049182.

Sally E. Thompson, Ciaran J. Harman, Peter A. Troch, Paul D. Brooks, and Murugesu Sivapalan. Spatial scale dependence of ecohydrologically mediated water balance partitioning: A synthesis framework for catchment ecohydrology. Water Resources Research, 47(10), may 2011. doi: 10.1029/2010wr009998. URL https : / / doi . org/ $10.1029 \div 2 \mathrm{~F} 2010 \mathrm{wr} 009998$.

Javier Valdes-Abellan, MA Pardo, and Antonio José Tenza-Abril. Observed precipitation trend changes in the western mediterranean region. International Journal of Climatology, 37:1285-1296, 2017.

Francesco Viola, A Francipane, D Caracciolo, D Pumo, G La Loggia, and LV Noto. Coevolution of hydrological components under climate change scenarios in the mediterranean area. Science of the Total Environment, 544:515-524, 2016.

S Zanardo, CJ Harman, Peter A Troch, PSC Rao, and M Sivapalan. Intra-annual rainfall 
variability control on interannual variability of catchment water balance: A stochastic analysis. Water Resources Research, 48(6), 2012.

Maciej A Zwieniecki and Michael Newton. Seasonal pattern of water depletion from soilrock profiles in a mediterranean climate in southwestern oregon. Canadian journal of forest research, 26(8):1346-1352, 1996. 